\begin{tabular}{|c|c|}
\hline Title & A novel current-tracking method for active filters based on a sinusoidal internal model [for PWM invertors] \\
\hline Author(s) & Fukuda, S.; Yoda, T. \\
\hline Citation & $\begin{array}{l}\text { IEEE Transactions on Industry A pplications, 37(3), } 888895 \\
\text { https://doi.org/10.1109/28.924772 }\end{array}$ \\
\hline Issue Date & $2001-05$ \\
\hline Doc URL & http:/hdl.handle.net/2115/5719 \\
\hline Rights & $\begin{array}{l}\text { (O)2001 IEEE. Personal use of this material is permitted. However, permission to reprint/republish this material for } \\
\text { advertising or promotional purposes or for creating new collective works for resale or redistribution to servers or lists, } \\
\text { or to reuse any copyrighted component of this work in other works must be obtained from the IEEE." } \\
\text { IEEE, IEEE Transactions on Industry A pplications } \\
\text {, 37, 3, 2001, p888 } 895\end{array}$ \\
\hline Tyре & article \\
\hline File Information & ITIA 37-3.pdf \\
\hline
\end{tabular}

Instructions for use 


\title{
A Novel Current-Tracking Method for Active Filters Based on a Sinusoidal Internal Model
}

\author{
Shoji Fukuda, Senior Member, IEEE, and Takehito Yoda
}

\begin{abstract}
A new current control method based on the internal model principle in control theory is proposed. It introduces a sinusoidal internal model into the control system. It does not use any coordinate transformations. The method can be used for tracking an arbitrary number of harmonics: a dc component or fundamental frequency component signal. It is applied to a single-phase pulsewidth modulation inverter and active filter. The validity is confirmed by simulation and experimental results.
\end{abstract}

Index Terms-Active filter, current control, internal model principle, pulsewidth modulation, pulsewidth modulation inverter.

\section{INTRODUCTION}

$\mathbf{M}$ ANY POWER electronic inverter applications, such as active filters (AFs), require an output current which can be designed to have a specified output frequency spectrum. If the system is three phase, the rotating reference frame produced by the synchronous $d-q$ coordinate transformation offers a useful solution because the synchronous $d-q$ transformation converts a fundamental reference frequency signal into a dc signal [1]. A conventional proportional and integral (PI) compensator can be applied to the variables in the rotating reference frame so as to achieve a zero steady-state error in response to step commands. Then, variables in the rotating reference frame must be restored in the stationary three-phase reference frame using the inverse $d-q$ transformation. Typical examples are seen in a current control system in ac drives [2].

However, if the system is single phase, the synchronous $d-q$ coordinate transformation cannot be applied. Also, if a disturbance in a three-phase system is dc, steady-state errors always remain, even if the synchronous $d-q$ coordinate transformation and a PI compensator are used.

To solve the above problems, this paper proposes a new stationary reference frame control method that is based on the internal model principle [3] from control theory. The method introduces a sine transfer function [4], [5] with a specified res-

Paper IPCSD 01-005, presented at the 2000 Industry Applications Society Annual Meeting, Rome, Italy, October 8-12, and approved for publication in the IEEE TRANSACTIONS ON INDUSTRY APPLICATIONS by the Industrial Power Converter Committee of the IEEE Industry Applications Society. Manuscript submitted for review May 1, 2000 and released for publication March 7, 2001. This paper was presented in part at the 8th European Conference on Power Electronics and Applications, Lausanne, Switzerland, September 7-9, 1999.

S. Fukuda is with the Systems and Information Division, Graduate School of Engineering, Hokkaido University, Sapporo 060-8628, Japan (e-mail: fukus@eng.hokudai.ac.jp).

T. Yoda was with the Systems and Information Division, Graduate School of Engineering, Hokkaido University, Sapporo 060-8628, Japan. He is now with Group-26, EV2, EHV Engineering Division, Development Center 4, Toyota Motor Corporation, Toyota 471-8572, Japan (e-mail: takehito@yoda.tec.toyota.co.jp).

Publisher Item Identifier S 0093-9994(01)04369-9. onant frequency into the current compensator. Thus, the gain of the open-loop transfer function of the control system goes to infinity at the resonant frequency, which ensures that the steady-state errors in response to step changes in a reference signal at that frequency reduce to zero. Furthermore, the proposed method removes the effects of a dc and ac disturbance with the resonant frequency.

In this paper, the proposed method is applied to only a singlephase system because a single-phase system is the best example to demonstrate the usefulness of the proposed method. However, the method is applicable to three-phase systems as well. In this case, the synchronous $d-q$ and inverse $d-q$ coordinate transformations, which are required when variables in a three-phase system are treated in the rotating reference frame, are not necessary.

\section{INTERNAL MODEL}

\section{A. Internal Model Principle}

The internal model principle implies that, in a feedback system, the output of a control object follows its reference input without a steady-state error if the system satisfies the following two conditions [3].

1) The closed system is asymptotically stable.

2) The open-loop transfer function of the system includes a mathematical model which can generate the required reference input.

Let us take a sinusoidal reference signal as an example and prove that the steady-state error will be zero, if the internal model principle is satisfied. Consider a simple feedback system, where the transfer functions of the compensator and the control object are $G_{c}(s)$ and $G_{r}(s)$, respectively. Let $R(s), E(s)$, and $Y(s)$ denote the reference, error, and output signal, respectively. Then, the open-loop transfer function $G_{0}(s)$ will be given by

$$
G_{0}(s)=G_{c}(s) G_{r}(s)=\frac{N_{0}(s)}{D_{0}(s)} .
$$

For the sinusoidal reference

$$
r(t)=A \cos \omega_{0} t \quad \text { or } \quad R(s)=\frac{A s}{s^{2}+\omega_{0}^{2}} .
$$

The error between $R(s)$ and $Y(s)$ can be expressed as follows:

$$
\begin{aligned}
E(s) & =\frac{R(s)}{1+G_{0}(s)}=\frac{D_{0}(s) R(s)}{D_{0}(s)+N_{0}(s)} \\
& =\frac{D_{0}(s)}{\left(s-\mu_{1}\right)\left(s-\mu_{2}\right) \cdots\left(s-\mu_{m}\right)} \frac{A s}{\left(s^{2}+\omega_{0}^{2}\right)}
\end{aligned}
$$


assuming, for simplicity of arguments, that the $\mu$ s are distinct. From condition 1), the poles of the closed system, $\mu \mathrm{s}$, must satisfy the following equation:

$$
\operatorname{Re}\left(\mu_{i}\right)<0 \text { for } i=1, \ldots, m .
$$

The error can also be expressed as

$$
E(s)=\frac{a_{1}}{s-\mu_{1}}+\cdots+\frac{a_{m}}{s-\mu_{m}}+\frac{b_{1}}{s-j \omega_{0}}+\frac{b_{2}}{s+j \omega_{0}}
$$

where the coefficients $b_{1}$ and $b_{2}$ are given by

$$
\begin{aligned}
b_{1}, b_{2} & =\left[\left(s \mp j \omega_{0}\right) E(s)\right]_{s= \pm j \omega_{0}} \\
& =\frac{D_{0}\left( \pm j \omega_{0}\right)}{D_{0}\left( \pm j \omega_{0}\right)+N_{0}\left( \pm j \omega_{0}\right)} \frac{A}{2} .
\end{aligned}
$$

Since $G_{0}(s)$ has poles $j \omega_{0}$ and $-j \omega_{0}$ from condition 2$)$, the denominator of $G_{0}(s)$ can be expressed as

$$
D_{0}(s)=\left(s^{2}+\omega_{0}^{2}\right) D_{0}^{\prime}(s)
$$

it follows that

$$
\begin{aligned}
D_{0}\left( \pm j \omega_{0}\right) & =0 \quad \text { and } \quad N_{0}\left( \pm j \omega_{0}\right) \neq 0, \quad \text { or } \\
b_{1} & =b_{2}=0 .
\end{aligned}
$$

Thus, the last two terms in (3-2) disappear, guaranteeing the reduction of the error to zero as time elapses. In a similar manner, it can be easily proved that the effects of an ac disturbance at the frequency $\omega_{0}$ can be eliminated.

\section{B. Sinusoidal Internal Model}

Consider the control system in which the reference input signal is sinusoidal. Based on the internal model principle, the compensator with a sinusoidal transfer function is required. There are two alternatives for the sine transfer function. One is the Laplace transform of a cosine function with a resonant frequency $\omega_{0}, G_{S 1}(s)$, and the other is that of a sine function $G_{S 2}(s)$. They are given by

$$
G_{S 1}(s)=\frac{s}{s^{2}+\omega_{0}^{2}} \quad G_{S 2}(s)=\frac{\omega_{0}}{s^{2}+\omega_{0}^{2}} .
$$

The Bode diagrams of $G_{S 1}(s)$ and $G_{S 2}(s)$ are compared in Fig. 1. It is observed that $G_{S 1}(s)$ has a sufficient amount of phase margin, $90^{\circ}$, but the phase margin of $G_{S 2}(s)$ is $0^{\circ}$. Therefore, if $G_{S 2}(s)$ were employed for the sinusoidal internal model, the feedback control system would probably be highly underdamped. This situation is examined by simulation studies.

Fig. 2 shows a simple current control system with a compensator which consists of a proportional, integral, and transfer function for a sine wave (PIS compensator). The current reference $i^{*}$ is a sinusoid with the amplitude of $5 \mathrm{~A}$ and the frequency of $50 \mathrm{~Hz}$. The load consists of $R=10 \Omega$ and $L=50 \mathrm{mH}$ connected in series. Responses when the resistance $R$ is increased stepwise from $10 \Omega$ to $20 \Omega$ at $0.04 \mathrm{~s}$ are simulated. The gains of the compensator are $K_{p}=40 \mathrm{~V} / \mathrm{A}$, and $K_{i}=K_{s}=4000$ $\mathrm{V} /(\mathrm{A} \cdot \mathrm{s})$. Fig. 3(a) shows the current responses when $G_{S 1}(s)$ is used for the sinusoidal internal model. One can observe that the error rapidly reduces to zero. Fig. 3(b) shows the responses
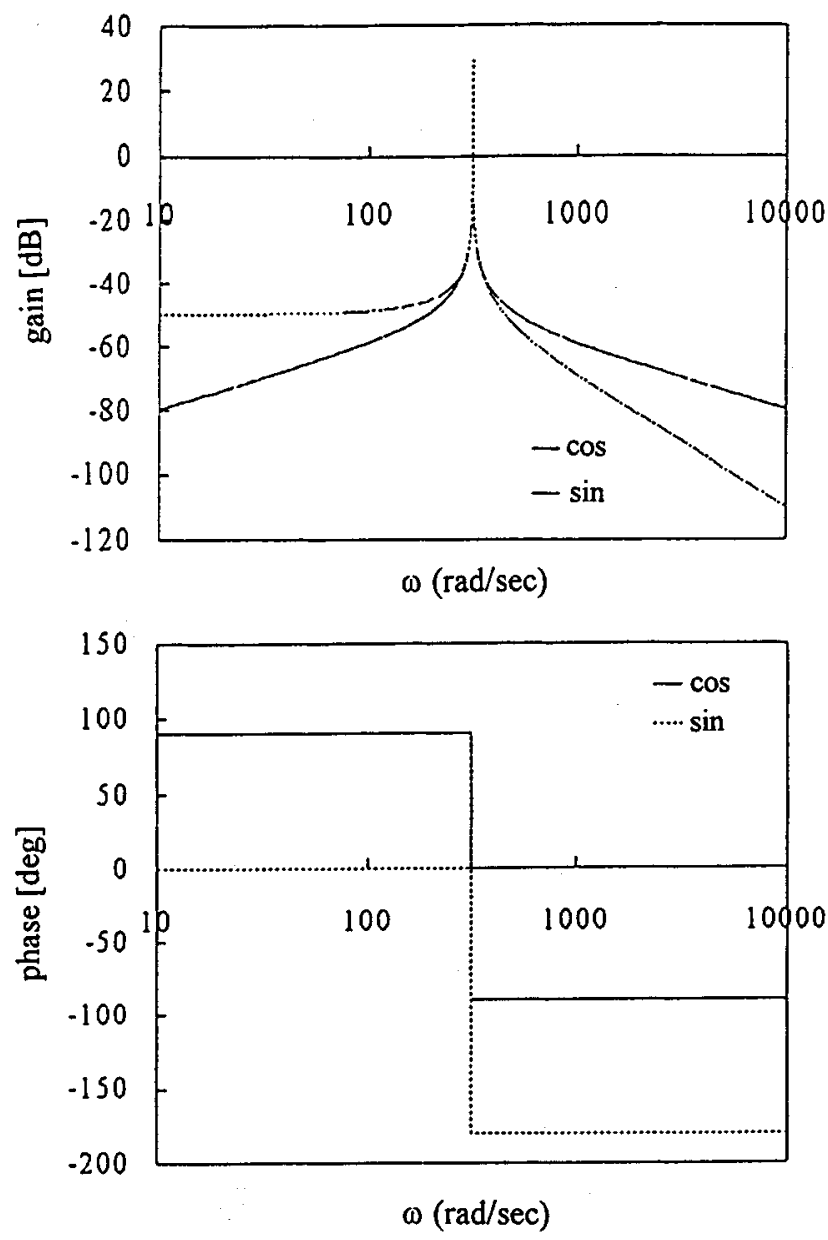

Fig. 1. Bode diagram of two sine transfer functions, cosine function $G_{S 1}(s)$, and sine function $G_{S 2}(s)$.

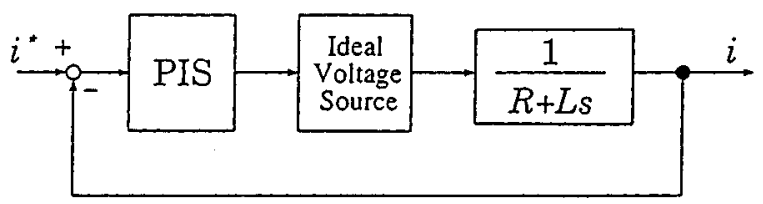

Fig. 2. Current control system using PIS compensator.

when $G_{S 2}(s)$ is used for the sinusoidal internal model. One can observe that the system is highly underdamped and the error reduces very slowly toward zero. This is because the phase margin is insufficient. Therefore, it is important to note that the cosine function $G_{S 1}(s)$ should be chosen for the sinusoidal internal model.

In this paper, $G_{S 1}(s)$ in (8) is called the sine transfer function. The gain of the sine transfer function is theoretically infinite at the resonant angular frequency, namely, the gain of the open-loop transfer function goes to infinity at $\omega=\omega_{0}$. Fig. 4 shows the block diagram of the sinusoidal internal model $G_{S 1}(s)$, where the input and output are $u$ and $y$, respectively, and the gain is $K_{S}$.

\section{PIS Compensator}

Fig. 5 shows a current control system of a single-phase pulsewidth modulation (PWM) inverter in which the compen- 


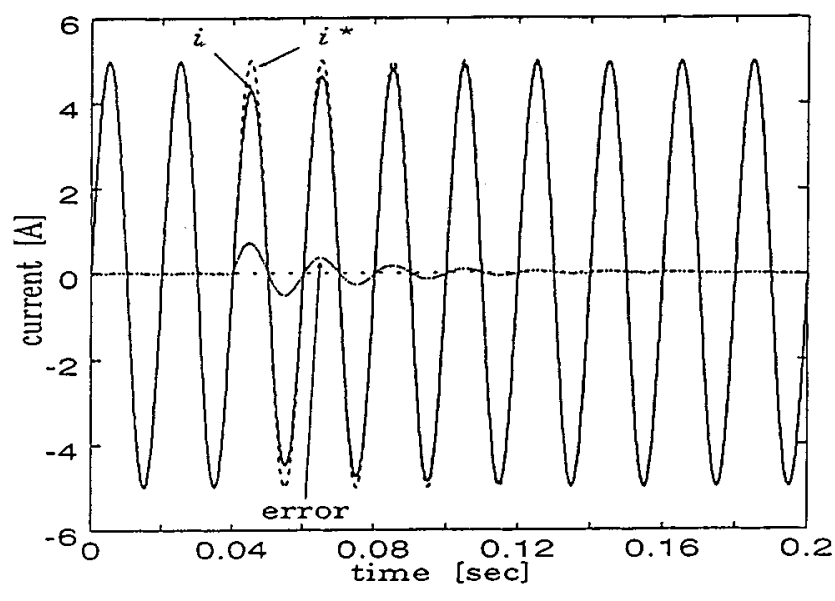

(a)

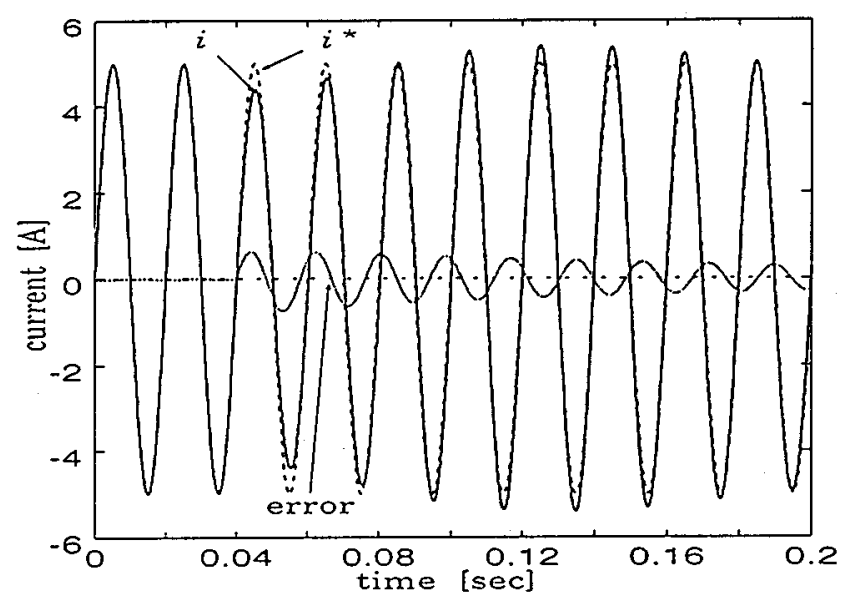

(b)

Fig. 3. Comparison of current responses to a step change in load resistance, $R=10 \Omega$ to $20 \Omega$ at 0.04 s. (a) With cosine function $G_{S 1}(s)$. (b) With sine function $G_{S 2}(s)$.

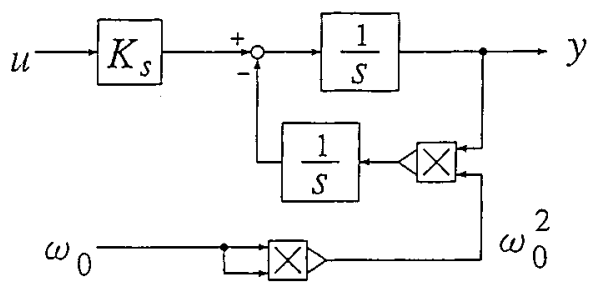

Fig. 4. Block diagram of sinusoidal internal model $G_{S 1}(s)$ based on cosine function.

sator consists of a proportional, integral and transfer function for a sine wave, i.e., the PIS compensator. The transfer function of the PIS compensator is

$$
G_{c}(s)=K_{p}+\frac{K_{i}}{s}+\frac{K_{s} s}{s^{2}+\omega_{0}^{2}}
$$

where $\omega_{0}$ denotes the resonant frequency of the sine transfer function and should coincide with the frequency of the sinusoidal reference input. It is noted that the second term of (9) constructs an internal model for a dc reference input. Thus, (9)

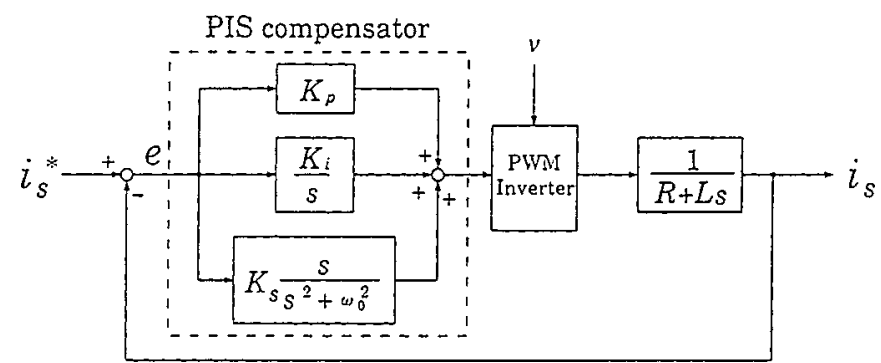

Fig. 5. Current control system of PWM inverter using PIS compensator.

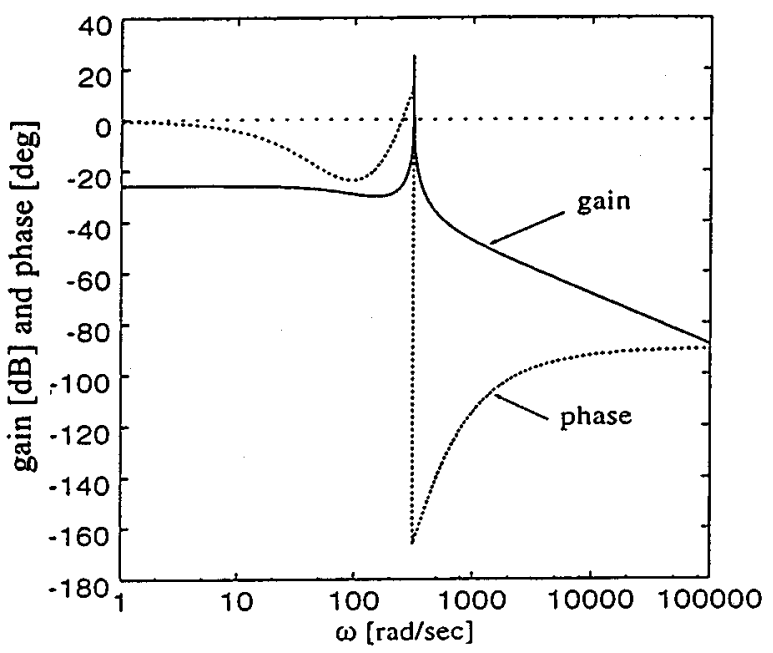

Fig. 6. Bode diagram of open-loop transfer function, $G_{0}(s)$ in (11) under $G_{\text {inv }}(s)=1$.

satisfies the second condition of the internal model principle for a dc signal and a sinusoidal reference signal with the frequency $\omega_{0}$.

\section{AC CURRENT CONTROL OF PWM INVERTER}

\section{A. Bode Diagram}

In Fig. 5, the inverter load is a simple $R-L$ circuit and its transfer function is

$$
G_{r}(s)=\frac{1}{R+L s} .
$$

Denoting that the transfer function of the PWM inverter is $G_{\text {inv }}(s)$, one has the open-loop transfer function given by

$$
G_{0}(s)=G_{c}(s) G_{\text {inv }}(s) G_{r}(s) \text {. }
$$

The Bode diagram of $G_{0}(s)$ is shown in Fig. 6, where $G_{\text {inv }}(s)$ is assumed unity. The gains and parameters are given in Section III-B.

It is observed that the gain exhibits almost an infinite value at the resonant frequency $\omega_{0}\left(=2 \pi f_{0}\right)$. This situation holds even if $G_{\text {inv }}(s)$ is not unity because $G_{c}(s)$ goes to infinity at $\omega=\omega_{0}$. The frequency band around $\omega_{0}$ has a high gain. Then, the steadystate error differs only slightly from zero if a small difference between the reference and resonant frequency exists.

Fig. 7 shows a phase margin versus gain $K_{s}$ characteristic of $G_{0}(s)$ under $G_{\text {inv }}(s)=1$. A higher $K_{s}$ tends to construct a more robust control system, but results in a smaller phase 


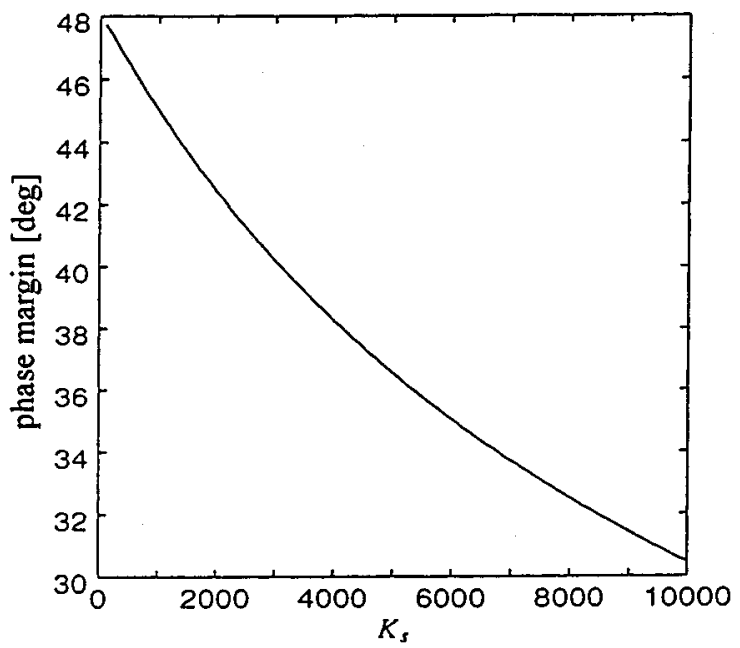

Fig. 7. Phase margin versus gain $K_{s}$ characteristic.

margin. Practically, a very high $K_{s}$ was not necessary as the following experimental results indicated.

\section{B. Experimental Results}

An experiment of current control using a single-phase PWM inverter was carried out in order to confirm the basic performance of the sinusoidal internal model. Fig. 5 shows the current control system. Two cases were investigated for comparison purposes: one was with a PI compensator and the other was with a PIS compensator. Since a dc component was not required in the reference current, the integral action was omitted at first. The gains were $K_{p}=0.3, K_{i}=0.0, K_{s}=150$, and $\omega_{0}=300 \pi$ for the PIS compensator, and $K_{p}=0.3$ and $K_{i}=0.0$ for the PI compensator. The dc input voltage of the PWM inverter was $150 \mathrm{~V}$. The load parameters were $R=6.0 \Omega$ and $L=80 \mathrm{mH}$. The amplitude and frequency of the reference output current of the inverter were $I^{*}=1 \mathrm{~A}$ and $f_{0}=50 \mathrm{~Hz}$, respectively. The unipolar PWM method [7] was used for the inverter control.

Waveforms at steady state when the PI and PIS compensator were used are compared in Fig. 8(a)-(c). Fig. 8(a) shows that a steady-state error exists when only the proportional (P) compensator was used. Fig. 8(b) shows that almost no steady-state error exists when the proportional and sine (PS) compensator was used, but a very small dc component can be observed in the error. Fig. 8(c) shows the waveforms when an integral action of $K_{i}=60$ was included (with the PIS compensator). Since the integral compensator constructs the internal model for a dc signal, the dc component disappeared in the error.

Responses to step changes are shown in Fig. 9(a) and (b). Fig. 9(a) shows responses when the resistance was reduced stepwise from $R=12 \Omega$ to $6 \Omega$ at $0.0425 \mathrm{~s}$ while keeping $I^{*}=1 \mathrm{~A}$. Fig. 9(b) shows responses when the reference current was increased stepwise from $I^{*}=1$ A to $2 \mathrm{~A}$ at $0.0452 \mathrm{~s}$ while keeping $R=$ $6.0 \Omega$. It is observed that, in both cases, the error reduced to zero in a stable fashion within a half cycle of the output frequency.

\section{Single-PhASE AF}

\section{A. Control System Design}

Fig. 10 shows the single-phase AF and its control system used for the experiment. A diode rectifier, which is the load, generates harmonic components in the load current $i_{L}$. The AF takes an inverted form of the load current harmonics, and sums them with the load current. The source current therefore contains only a fundamental component.

Let the load current including a dc component be

$$
i_{L}=I_{0}+\sum_{m=1}^{\infty} I_{m} \sin \left(m \omega_{1} t-\phi_{m}\right), \quad m=1,3,5, \ldots
$$

where $m$ takes on only odd integers. If all harmonic components are to be compensated for, the current reference of the AF should be

$$
i_{C}^{*}=I_{1} \sin \left(\omega_{1} t-\phi_{1}\right)-i_{L}
$$

If, for example, up to the $n$th harmonic components are to be compensated for, the current reference of the AF will be

$$
i_{C}^{*}=-I_{0}-\sum_{m=3}^{n} I_{m} \sin \left(m \omega_{1} t-\phi_{m}\right) .
$$

Then, the transfer functions of the overall compensator should be given by

$$
\begin{array}{r}
G_{C}(s)=K_{p}+\frac{K_{i}}{s}+\sum_{m=1}^{n} \frac{K_{s m} s}{s^{2}+\left(m \omega_{1}\right)^{2}}, \\
m=1,3,5 \ldots, n .
\end{array}
$$

The sinusoidal transfer function for the fundamental component is introduced in (15) to suppress the effects of the ac mains voltage with the frequency $\omega_{1}$ which acts as a disturbance. It is also useful to compensate for the reactive component with the fundamental frequency $\omega_{1}$.

Fig. 10 also shows the control system of the single-phase AF. There are two control performance criteria.

1) DC voltage $V_{\mathrm{dc}}$ should coincide with its reference $V_{\mathrm{dc}}^{*}$.

2) Compensation current $i_{C}$ should follow its reference $i_{C}^{*}$ as closely as possible.

There are two control loops, the dc voltage control loop with a PI compensator and the output current control loop with a PIS compensator.

The PI compensator is used to accomplish the first criterion. It generates the amplitude of the current reference $I_{\mathrm{dc}}$ for the $V_{\mathrm{dc}}$ control. The current $I_{\mathrm{dc}}$ is, then, multiplied by a sinusoidal signal with unit amplitude, $u$, which is synchronized and in phase with the ac terminal voltage $v$, and becomes an ac current reference signal for the $V_{\mathrm{dc}}$ control, $i_{v \text {-cont }}$. The sum of $i_{C}^{*}$ and $i_{v \text {-cont }}$ constitutes the reference signal for the PIS compensator.

The PIS compensator is used to accomplish the second criterion. It processes the current error and makes the voltage reference signal for the PWM converter which forces the actual 


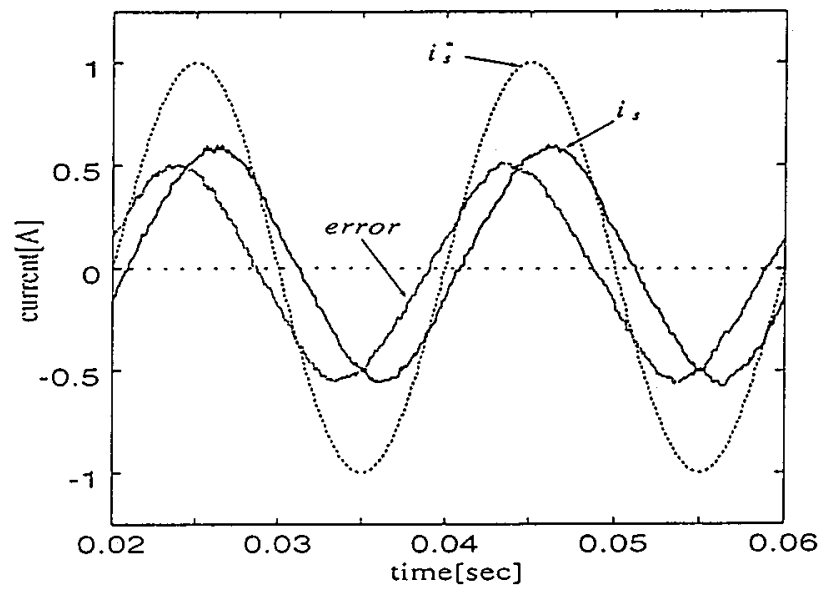

(a)

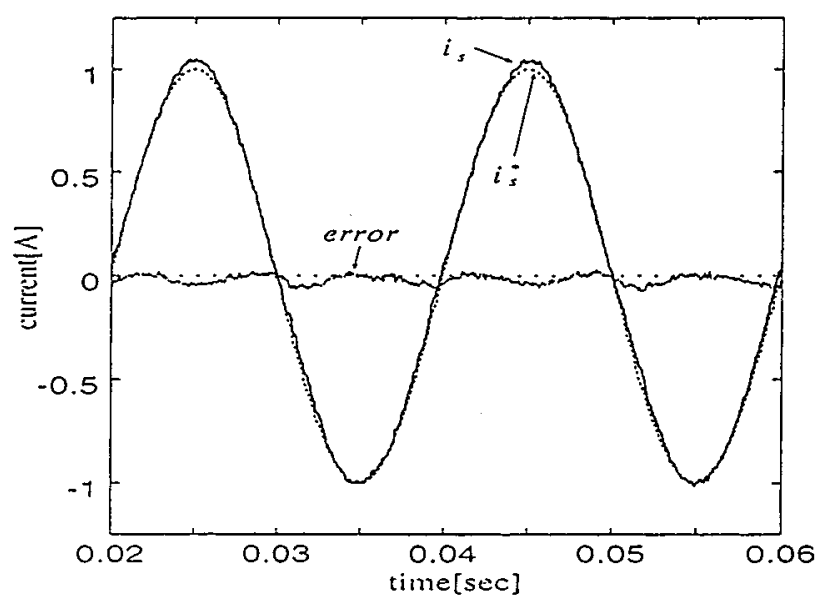

(b)

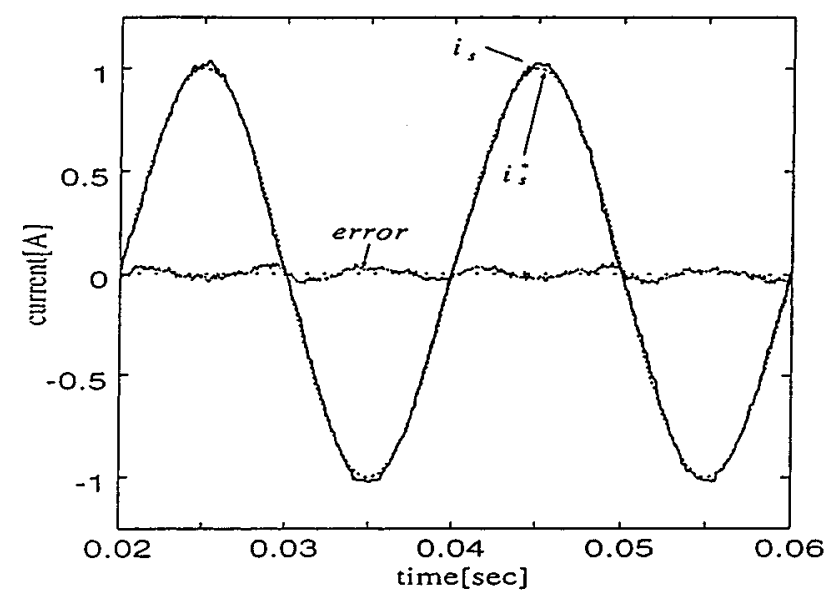

(c)

Fig. 8. Comparison of load current and steady-state error. (a) With P compensator. (b) With PS compensator. (c) With PIS compensator.

current $i_{C}$ to follow its reference $i_{C}^{*}+i_{v \text {-cont }}$ as closely as possible. Gating signals for the converter power devices are obtained using the unipolar PWM method [6], which is the comparison-based method between a single triangular carrier wave and two reference voltage signals with an opposite phase each other.

\section{B. Experimental Results}

A small-capacity single-phase AF system was built and experiments were carried out using it. The PIS compensator of the AF consisted of the sinusoidal transfer functions for the 1st, 3rd...19th harmonic components (all odd integers up to 19), which were implemented using a digital signal processor (DSP) TMS320C32. A proportional action was included in the PIS compensator to improve the dynamic responses, but the integral action was omitted because a dc component was not required in the reference.

The parameters and gains used are shown in Table I. These gain values were selected so that the open-loop transfer function of the AF had a sufficient amount of phase margin. The resonant frequency was $\omega_{0}=\omega_{1}$, constant. The method proposed in [7] was used for calculating the harmonic and reactive component of the load current.
Fig. 11(a) shows waveforms of the load current $i_{L}$, the source current $i_{S}$, and the compensation current $i_{C}$ of the $\mathrm{AF}$ when only the PI compensator was used. Also, it shows the frequency spectrum of the lower order harmonic components of $i_{S}$. One can observe that the compensation was not good enough and the total harmonic distortion (THD) value of $i_{S}$ was $7.13 \%$, while the THD value of $i_{L}$ was $27.0 \%$.

Fig. 11(b) shows waveforms of the load current $i_{L}$, the source current $i_{S}$, and the compensation current $i_{C}$ when the PIS compensator was used. Also it shows the spectrum of the lower order harmonic components of $i_{S}$. One can observe that the lower order harmonic components in $i_{L}$ were well suppressed and they almost disappeared in the $i_{S}$ waveform. The THD value of $i_{S}$ was drastically reduced to as low as $1.74 \%$. It is clear that the application of the sinusoidal internal model to an AF control system is very useful.

\section{Comparison With Conventional Current Control}

In conventional AFs, only a $\mathrm{P}$ compensator is used in the current control system. The proportional gain $K_{p}$ should be high to obtain a small steady-state current error. However, if $K_{p}$ were very high, the carrier frequency component in the load current would be amplified and appear in the output resulting in unde- 

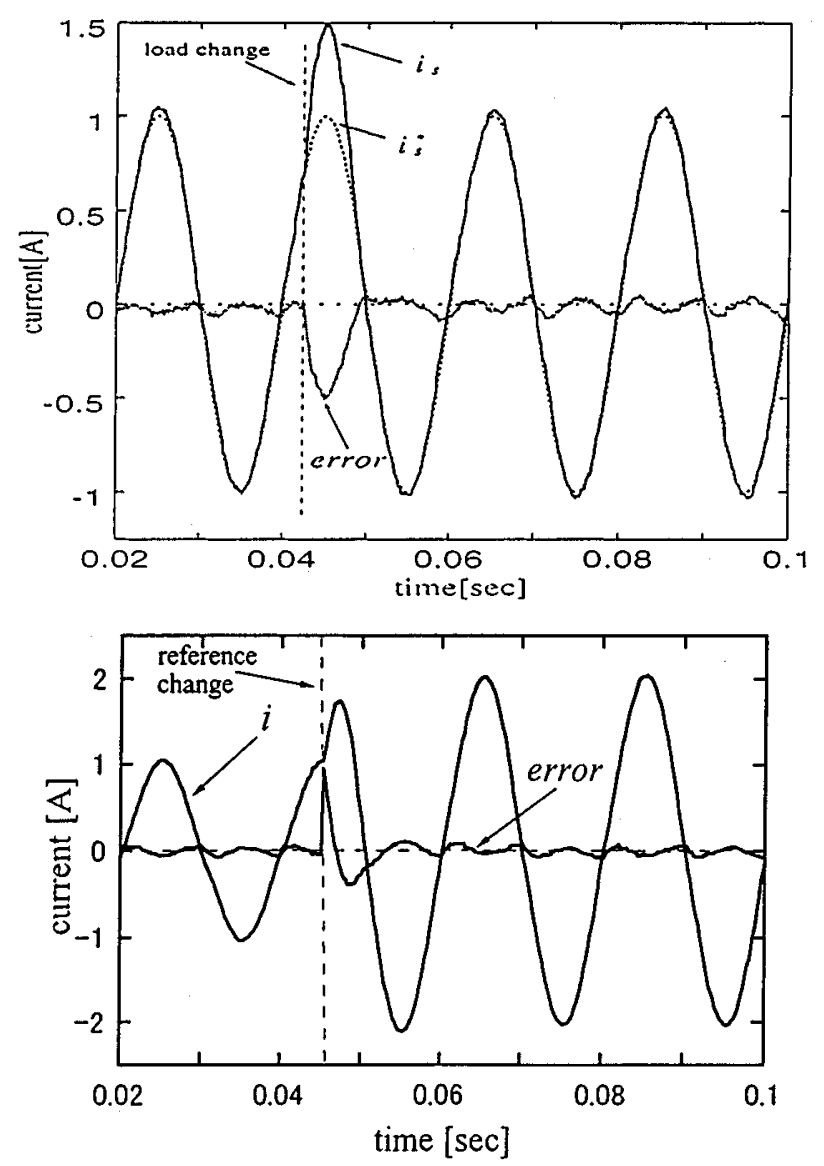

Fig. 9. Transient responses with PIS compensator, $K_{i}=60$. (a) Step load change, $R=12 \Omega$ to $6 \Omega$ at $0.0425 \mathrm{~s}$. (b) Step reference change, $I^{*}=1$ A to $2 \mathrm{~A}$ at $0.0452 \mathrm{~s}$.

sirable performance of AF. Thus, a very high gain cannot be designed for $K_{p}$; as a result, some current error always remains in the output. The effect of a disturbance remains in the output as well.

However, if a PIS compensator having the resonant frequency $\omega_{0}$ is used, the following advantages can be found compared with a conventional P or PI compensator.

1) A high proportional gain $K_{p}$ is not necessary because the gain of the closed loop is infinitely high at the wanted frequencies, $\omega=\omega_{0}$ and $\omega=0$. Hence, the carrier frequency components cannot be amplified.

2) The effects of a dc and ac disturbance with the resonant frequency can be removed.

3) The PIS compensator provides a very robust AF control system. It guarantees that the steady-state current error does not exist even if the parameters, excluding the frequency to be filtered, vary as far as the variation is within the limit with which the closed loop is kept stable.

4) By combining plural $\mathrm{S}$ compensators having resonant frequencies $\omega_{01}, \omega_{02}, \omega_{03}, \ldots$, only the specified harmonic components at the frequencies $\omega_{01}, \omega_{02}, \omega_{03}, \ldots$, can be filtered just like a combination of plural passive $L C$ filters tuned at the respective frequencies.

5) The PIS compensator is also useful for three-phase systems. The above-mentioned advantages also hold in threephase AFs.

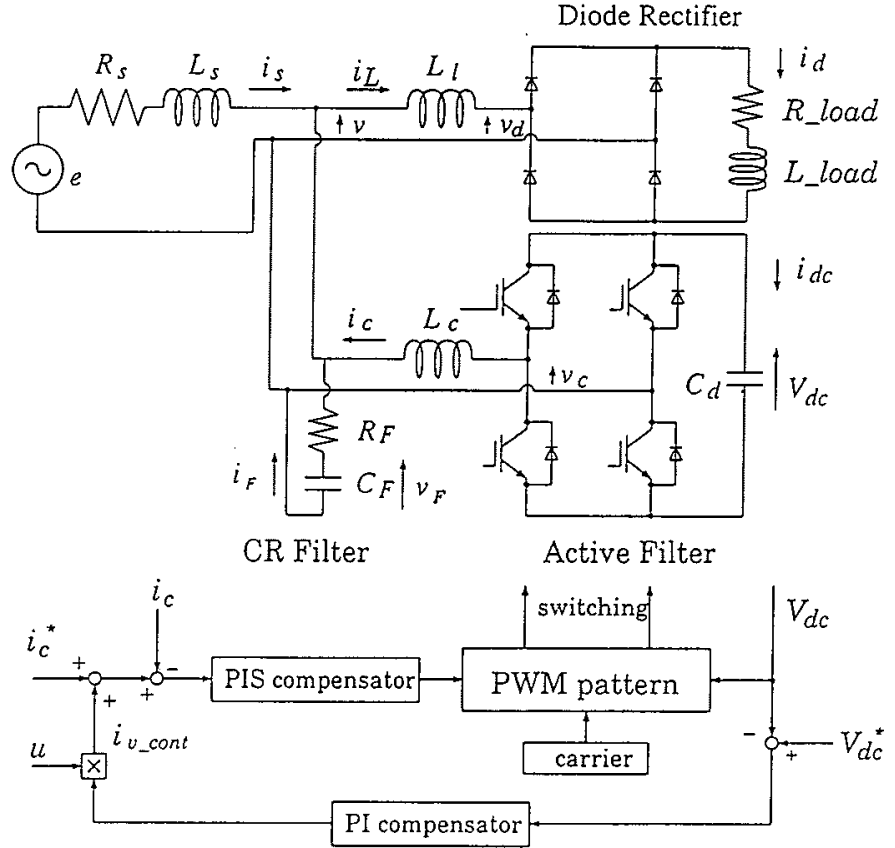

Fig. 10. Single-phase AF and its control system.

However, it should be noted that the compensator transfer function for a sine wave (S compensator) is inherently sensitive to frequency variations. If the frequency to be filtered varies in a wide range like harmonic currents generated by a cycloconverter, the corresponding resonant frequency of the $\mathrm{S}$ compensator, $\omega_{0}$, must be adjusted to track the varying harmonic frequency. Also, if a large frequency deviation occurs in the utility, some current error may remain. In this situation, $\omega_{0}$ must be regulated to track the utility frequency using a phase-locked loop (PLL).

\section{CONCLUSION}

This paper has proposed a novel current control method suitable for tracking an arbitrary number of harmonics: a dc component or fundamental frequency component signal. The idea is based on the internal model principle from control theory. The method requires an $\mathrm{S}$ compensator that can result in zero steady-state current-tracking error for sine wave set points.

The PIS compensator constructs a very robust current control system. However, the $\mathrm{S}$ compensator is inherently sensitive to a difference between the reference and resonant frequency. If deviations in the mains frequency are large in $\mathrm{AF}$ applications, a PLL can be used for regulating the resonant frequency in accordance with the variations in the mains frequency.

If a PIS compensator is employed in a control system, the following occur.

- The transfer function of the open loop exhibits a large phase change around the resonant frequency where the gain is large.

- The phase margin of the open loop decreases with an increase in the $\mathrm{S}$ compensator gain.

The above two points may suggest stability problems in the control systems if the PIS compensator is used. However, it was easy to select gain values that provide a sufficient phase margin 
TABLE I

PARAMETERS AND CONTROL GAINS OF ACTIVE FILTER.

\begin{tabular}{|c|c|c|c|c|c|}
\hline $\begin{array}{l}\text { AC mains voltage } \\
\text { frequency }\end{array}$ & $\begin{array}{l}E \\
f_{1}\end{array}$ & $\begin{array}{l}100 \mathrm{~V} \\
50 \mathrm{~Hz}\end{array}$ & \begin{tabular}{|r|} 
PI compensator: \\
proportional gain \\
integral gain
\end{tabular} & $\begin{array}{l}K_{p} \\
K_{i}\end{array}$ & $\begin{array}{l}0.3 \\
0.0\end{array}$ \\
\hline $\begin{array}{l}\text { carrier frequency } \\
\text { sampling frequency }\end{array}$ & $\overline{f_{c}}$ & $\begin{array}{l}10 \mathrm{kHz} \\
10 \mathrm{kHz}\end{array}$ & $\begin{array}{c}\text { S compensator gains: } \\
k=1,3, \ldots \ldots \ldots, 19\end{array}$ & $K_{*}$ & 150 \\
\hline $\begin{array}{l}\text { load resistance } \\
\text { inductance }\end{array}$ & $\begin{array}{l}R_{\text {load }} \\
L_{\text {load }}\end{array}$ & $\begin{array}{r}6.4 \Omega \\
80.0 \mathrm{mH} \\
\end{array}$ & $C R$ filter & $\begin{array}{l}R_{F} \\
C_{F}\end{array}$ & $\begin{array}{r}5.5 \Omega \\
4.0 \mu \mathrm{F}\end{array}$ \\
\hline AC reactor: & $\begin{array}{l}R_{c} \\
L_{c}\end{array}$ & $\begin{array}{r}0.4 \Omega \\
5.0 \mathrm{mH}\end{array}$ & $\begin{array}{r}\text { DC voltage control: } \\
\text { reference voltage } \\
\begin{array}{r}\text { proportional gain } \\
\text { integral gain }\end{array}\end{array}$ & $\begin{array}{l}V_{d c}^{*} \\
K_{v p}^{*} \\
K_{v i}\end{array}$ & $\begin{array}{r}150 \mathrm{~V} \\
0.00005 \\
0.0001 \\
\end{array}$ \\
\hline load side reactor & $L_{t}$ & $5.0 \mathrm{mH}$ & DC capacitor & $C_{d}$ & $1000 \mu \mathrm{F}$ \\
\hline
\end{tabular}
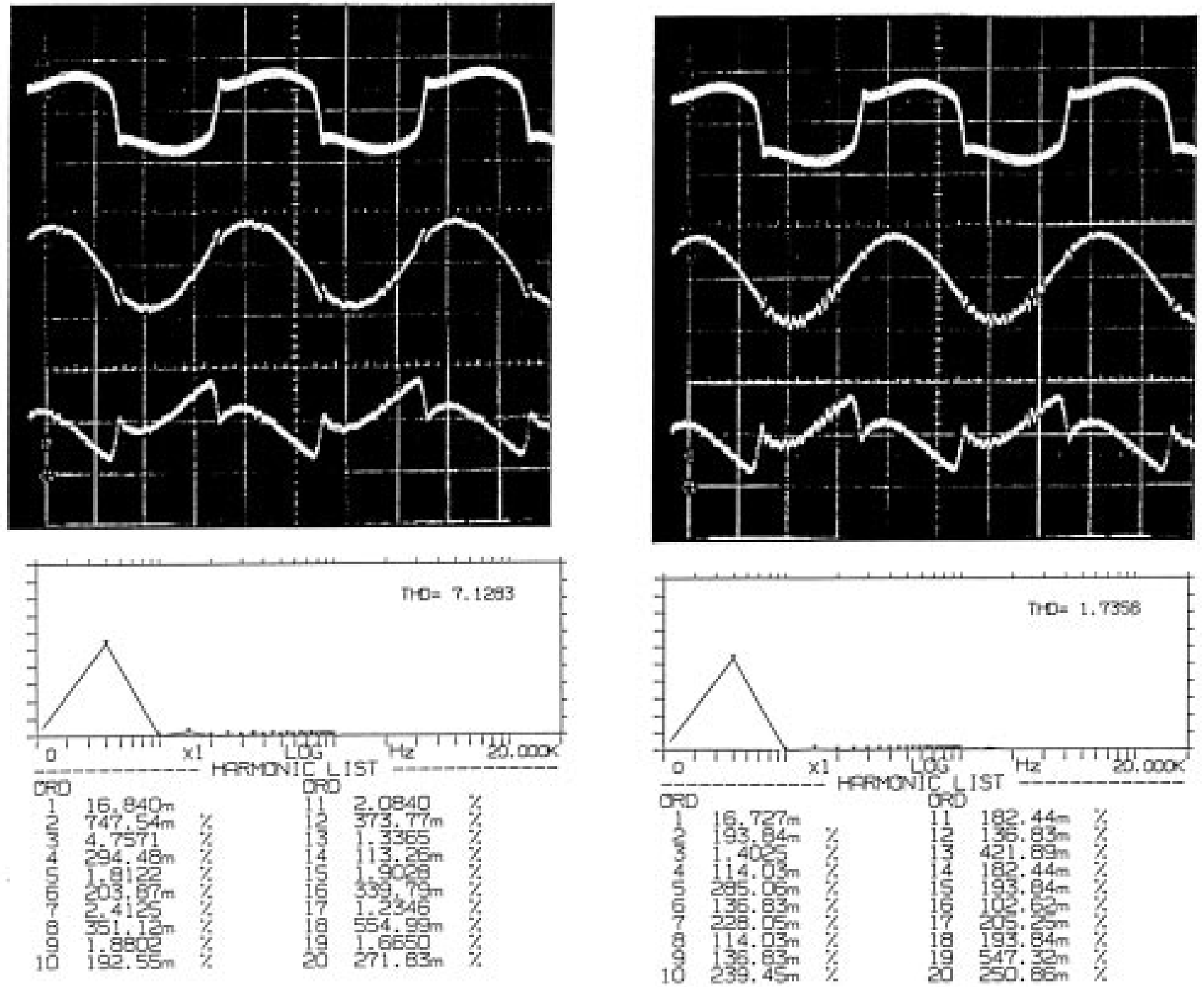

(a)

(b)

Fig. 11. Comparison of current waveforms. Upper: load current $i_{L}$; middle: source current $i_{S}$; lower: AF output current $i_{C} .5 \mathrm{~A} / \mathrm{div}$ and $5 \mathrm{~ms} / \mathrm{div}$, and frequency spectrum of source current $i_{S}$. (a) With PI compensator. (b) With PIS compensator.

and excellent control performance. The authors have not experienced any stability problems in their experiment.
Several applications of the proposed method using the PIS compensator have been presented and verified by simulation 
and experimental results using a single-phase PWM inverter and AF.

It is confirmed using a PWM inverter that the steady-state error for a sinusoidal current reference has been zero. A set of sine transfer functions that results in almost the perfect tracking of harmonic components has been verified using an AF application.

It is obvious that the proposed method is applicable to threephase systems, too. An optimal gain design for the PIS compensator will be a future research project.

The addition of a damping term to the $\mathrm{S}$ compensator may be useful for further improving both the stability and robustness against the mains frequency deviations without selecting a higher $\mathrm{S}$ compensator gain. This is also a future research project.

\section{REFERENCES}

[1] C. V. Jones, The Unified Theory of Electrical Machines. London, U.K.: Butterworth, 1967.

[2] D. W. Novotny and T. A. Lipo, Vector Control and Dynamics of AC Drives. Oxford, U.K.: Oxford Science, 1996

[3] M. Nakano and T. Mita, Basic Control Theory (in Japanese). Tokyo, Japan: Shokohdo, 1993.

[4] T. Yoda, D. Sakai, and S. Fukuda, "An ac current control method for single-phase converter based on an internal model principle" (in Japanese), in Proc. IEEJ-IAS Annu. Meeting, vol. 1, 1998, pp. 69-72.

[5] S. Fukuda and T. Yoda, "Investigation of current controller for single phase PWM converter based on the internal model principle," in Proc. EPE'99, 1999, CD-ROM.

[6] N. Mohan, T. Undeland, and W. Robbins, Power Electronics. New York: Wiley, 1995.

[7] J. Doval, A. Nogueiras, C. M. Penalver, and A. Lago, "Shunt active power filter with harmonic current control strategy," in Proc. IEEE PESC'98, 1998, pp. 1631-1635.

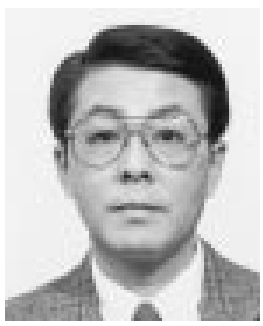

tive filters.

Dr. Fukuda is a member of the Institute of Electrical Engineers of Japan.

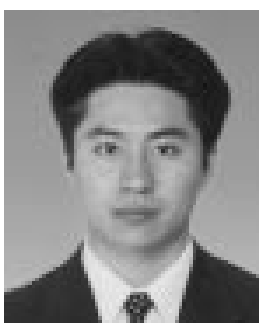

Takehito Yoda was born in 1975. He received the B.S. and M.S. degrees in electrical engineering from Hokkaido University, Sapporo, Japan, in 1998 and 2000 , respectively.

In 2000, he joined Toyota Motor Corporation, Toyota, Japan, where he is currently engaged in the development of battery control systems for hybrid vehicles in the EHV Engineering Division.

Mr. Yoda is a member of the Institute of Electrical Engineers of Japan. 